\title{
Optimization of public bus transport in Istanbul
}

\author{
M. Ergun, N. Caliskan \& S. Topuz Kiremitci \\ Technical University of Istanbul, Turkey
}

\begin{abstract}
Istanbul's public transport is very complex with many interactions between different modes of transportation, carriers and new projects. All of them had to be considered in this project, with the knowledge that the optimization had to be focused on the public bus transport provided by the IETT Company. Due to the lack of available basic demand data for private busses, only scheduled services can be considered and not passenger requested services.

For public bus transport (mainly company busses), the demand data was gathered from counting data and the Intelligent Ticketing System (Akbil) data. This is the central basic data of the project. Additionally the data for bus, railway, light railway and seaway transportation were handed over and adapted to build up the digital public transport model.

After the detailed analysis of the network model and its visualisation and reporting features, the weak points of the existing network were found (e.g. parts with low capacity usage of vehicles). Beside the very time intense development of the public transport model, the finding of adequate solutions and proposals for the amelioration of the actual situation was a main task of this project. Different general modes of optimization were found, described and defined in close adjustment with the IETT Company.

The study shows the positive effects that can be achieved by different kinds of optimization. Further on, it gives practical examples for the different kinds of optimization and shows the results from the IETT Company - and passenger point of view. Some improvements are suggested for a more efficient public bus system. Finally, the numbers of the maximum possible savings for the complete region of Istanbul without cutting down the quality of transportation for passengers are given.

With the realisation of the suggested improvements for the IETT Company bus traffic, the IETT Company can save a lot of money. The passengers will find faster bus lines and reduced travel times; however, the number of transfers between lines will increase. With the supposed acceleration of bus transportation on the future backbone network, there will be a flexible, high quality and reliable bus transportation system for Istanbul to face the challenges of the future.

Keywords: public transportation, macro simulation, optimisation.
\end{abstract}




\section{Introduction}

Public transport in large metropolitan regions like Istanbul will always play a key role in the daily life and the economic process. A high population density, long travel distances between the housing areas and the city centre or important business districts and limited space for roads are characteristics of the urban area at the Bosporus.

Due to the city development along the coast of the Sea of Marmara the seaway lines make fast and reliable connections between many important parts of Istanbul. These seaway connections play an important role in the connection of the Asian and the European side of the Bosporus. With the Marmaray project, the rail tunnel between Europe and Asia and the additional improvement of the rail infrastructure, there will be an important shift from seaway lines to the new railway lines as the railway serves the main ports of the seaway lines also.

With the seaway- and the railway lines travelling on their own tracks, without interference of other traffic as most of the metro and LRT-Lines also, they serve as a backbone of the public transport of Istanbul. But large areas of the Istanbul metropolitan region, mainly in the Asian part, and most of them far off the coast and the coastal railway have today no fast and reliable public transport system. These areas depend on the busses that circulate together with the private cars on the roads and highways. The bus passengers frequently suffer from the long travel times due to the many traffic jams on the major road network.

In addition, the bus traffic in the crowded inner city in the districts of Eminönü, Fatih, Beyoglu, Besiktas, Sisli and Uskudar is very slow because of the lack of own bus lanes. This is inefficient and expensive for the bus companies - without any use for the public.

The IETT as the major provider of bus services in the Istanbul metropolitan region wants to improve its services and adapt the bus network to the major changes in the public transport network that will be realized in a few years from now.

The main tasks can be described as follows: Reduction of parallel traffic of busses and railway, Adaptation of the IETT- bus lines to the demand, Optimization of connections between transfer points, Proposals for acceleration of busses

In addition to these tasks IETT proposed some guidelines for the general structure of the future network. Most important is the limitation of bus-lines to a length of not more than $20 \mathrm{~km}$. This will help to increase the reliability of the separate lines because the delays will not stretch over the whole travel-length of the long lines, sometimes more than $50 \mathrm{~km}$ today.

\section{Current situation of Istanbul's public transport}

The rapidly growing region of Istanbul has up-to-date within the city range approximated 10 millions and in the region approximated 15 millions inhabitants on a total area of $5.220 \mathrm{~km}^{2}$ [1]. Estimations proceed an increase of the population around 0.5 million each year for the coming years, which 
differentiates Istanbul clearly from other European cities. This rapid growth, in interaction with the local fastidious conditions is a big challenge for the public transport. Despite the large portion of traffic in particular over the two bridges is a bottleneck for the traffic. There are planning for a third bridge, a railway tunnel and possibly also a tunnel for motor vehicles, but they alone cannot solve the traffic problems in Istanbul. The railway system is still in development. It is not as fast adaptable and flexible as the bus system. But, railways have a clearly higher capacity and have an own line way without conflicts and interactions with the individual traffic. To get an impression of the public transport in Istanbul, one the most important topics is the knowledge of the mobility and behaviour of the passengers. The maximum transports at one day for the different modes of transportation are about as the following, fig. 1 [2]:

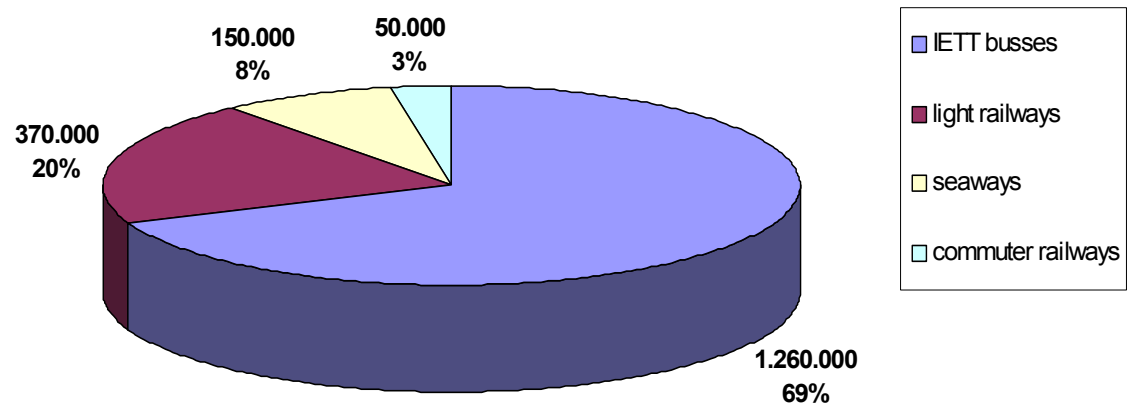

Figure 1: $\quad$ Passengers per day in the OD-Matrix.

This figure just shows the amount and percentages of the passengers out of the OD-Matrix. Other travels e.g. in private busses, cars and by foot cannot be considered, because the origin of this data is the Akbil (Smart) Ticketing System.

There are many authorities in Istanbul, which are responsible for the public transport. The IETT is responsible for the bus transport, funicular and nostalgic tramways. For the railway it is the TCDD, for the seaways it is the IDO and for the LRT, the metro and the tramway lines, the Ulasim A.S is the responsible operator. The Ulasim A.S. operates the very important Zeytinburnu - Kabatas and Zeytinburnu - Bagcilar tramway lines, the Aksaray - Airport LRT line and the Taksim - 4. Levent metroline.

\section{Digital public transport model}

Prerequisite for the optimization of an existing network of public transport is a computer-model of the whole traffic systems. The basic information items of the model (e.g. bus stops, line routes, departure times...) are given by different authorities in different formats. A lot of transformations and adaptations of the data is made. Finally, all the different given data was implemented with the specific requirements of the used programme (VISUM) in the digital model [3]. 
The dependencies of the different types of transport like railway, seaways and bus made it necessary to build up a model that reproduces the status quo of the current public transport situation. After the iterative and long lasting calibration of the model with the repeated changing of network parameters (e.g. line length, speed, capacities...) and checking of the given basic data of the origin destination matrix, the real planning process was started.

The model now can be used to deliver the results of proposed changes for different scenarios in detailed lists and figures for every single network item (e.g. line, traffic system, road section, bus-stop...).

For a more detailed projection of the changes it would be necessary to model the private car transport also, in addition to the public transport. Major improvements of the public transport always generate new passengers that have been car users before. With the given project goals and the tight schedule, this study just covers the public transport view. Nevertheless, the network model gives valid information about the general impact of the suggested improvements of the network.

The engineering knowledge and the immense amount of work to generate the digital model out of the basic data is described in detail, as well as the assumed facts and the final result of the model. It is very important to mention, that the calibrated digital public transport model can now be used for further detailed studies of selected measures concerning single lines, small regions or other general assumptions of the Istanbul region. Most important for the final results is the quality of the OD-matrix. This data was given by Sertem for all the 452 traffic cells. The more traffic cells are used, the better the result gets. And as usually the geographical size of the cells increases with the distance from the city-centres in Eminönü and Kadiköy. Included in the matrix are all the passengers of the IETTbuses, the railways (including LRT and tram) and the seaways. Not part of the model and therefore not in the matrix are the persons that travel with the private buses or the minibus. So in the project, we cannot declare and consider anything, related to the load on the private buses. But of course these lines and schedules are integrated in the digital public transport model.

As there was no need to make calculations for scenarios in the far future, it is alter the matrix for different scenarios. For a network development in longer time-horizons there would have been the necessity to calculate the impact of new housing areas and major city-developments. For a detailed scenario that takes the passenger shifts between public transport and private car-traffic in regard, we would have needed more detailed data of all the people travelling in Istanbul and much more time. So this was not part of the study.

The following fig. 2 shows the process of distributing the demand on the public transport network in the Digital public transport model.

Most interesting for the planning (e.g. for new lines) are the strongest relations in the OD-matrix. Relations with more than 1.000 persons per day have enough potential to require an own direct bus line that travels every hour or every 30 minutes in the peak hours. As these relations are mostly in the central part of the city and the bus network there is already relatively dense, there is not much need for new direct line routes as can be seen in fig. 3 below. 


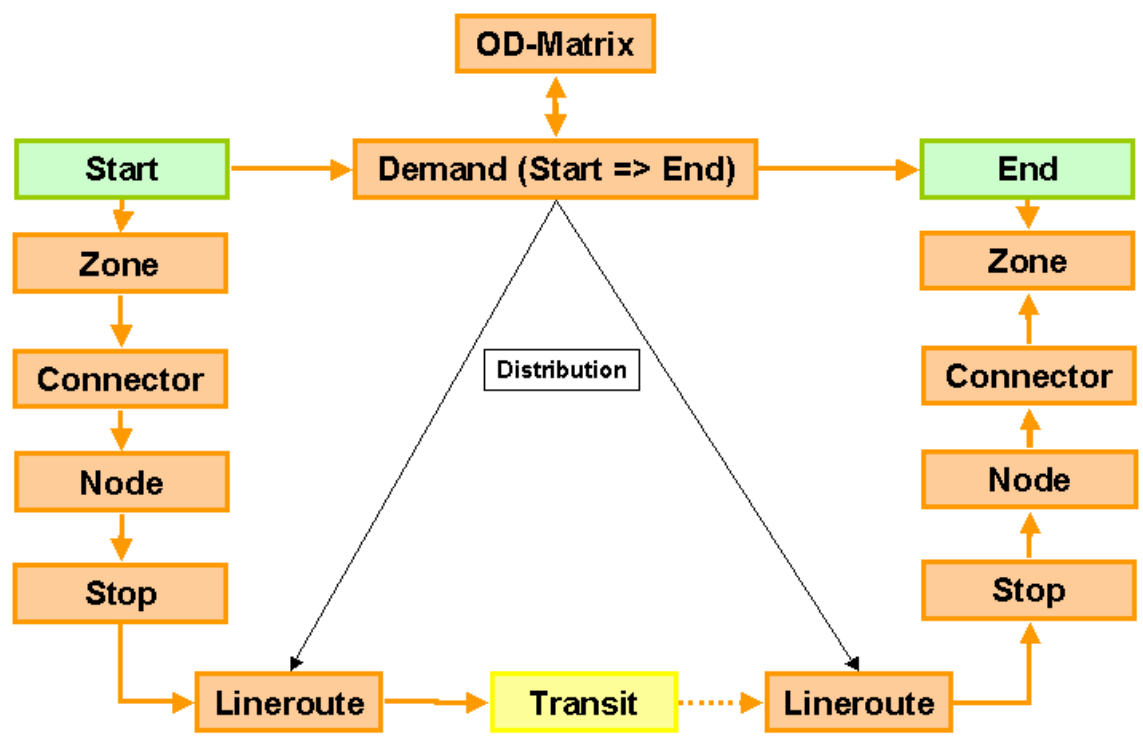

Figure 2: Distribution of the demand on the public transport network.

An important topic to mention is that the original OD-Matrix had to be modified after the introduction of the different planning proposals in the digital public transport model. The reason is the bigger attraction of the new defined bus network. More people will use it, when travel times are reduced and the offer is more convenient.

The process of modelling a traffic-system with the VISUM-programme makes several general assumptions necessary in order to rebuild the real situation as good as possible. Transfer time between vehicles of the same system (walking and waiting) $=$ global 10 minutes, between systems (bus, rail, ferry) $=$ global 10 minutes, time to reach the first bus stop from the cells $=$ global 5 or 10 minutes, depending on the size of the cell, calculations are made for the peak-hour, assumed as $11,3 \%$ of OD-matrix.

The complete road network of Istanbul that was used for the modelling can be described by these general figures which did build the base for the up following public transport model: 33 districts, 452 zones, 24.226 nodes, 62.218 links, 3.209 stops, 981 line routes. The current generated digital public transport model of Istanbul has the following outstanding benchmark values: 437 lines served by IETT buses, 152 lines shared with private buses, $24.150 \mathrm{Km}$ of total length of lines (both directions), 4.100 bus stops, 1,9 million passengers per day (out of the OD-matrix), 212.500 passengers in the morning peak hour $(11,3 \%$ of passengers), 26 million passenger kilometres per day, 1,4 million passenger hours per day, 490.000 bus kilometres per day.

The planned and modified new public transport network will be compared with these values of the basic model. Of course only the values for the IETT bus transportation will be considered when the changes for the IETT are calculated. 


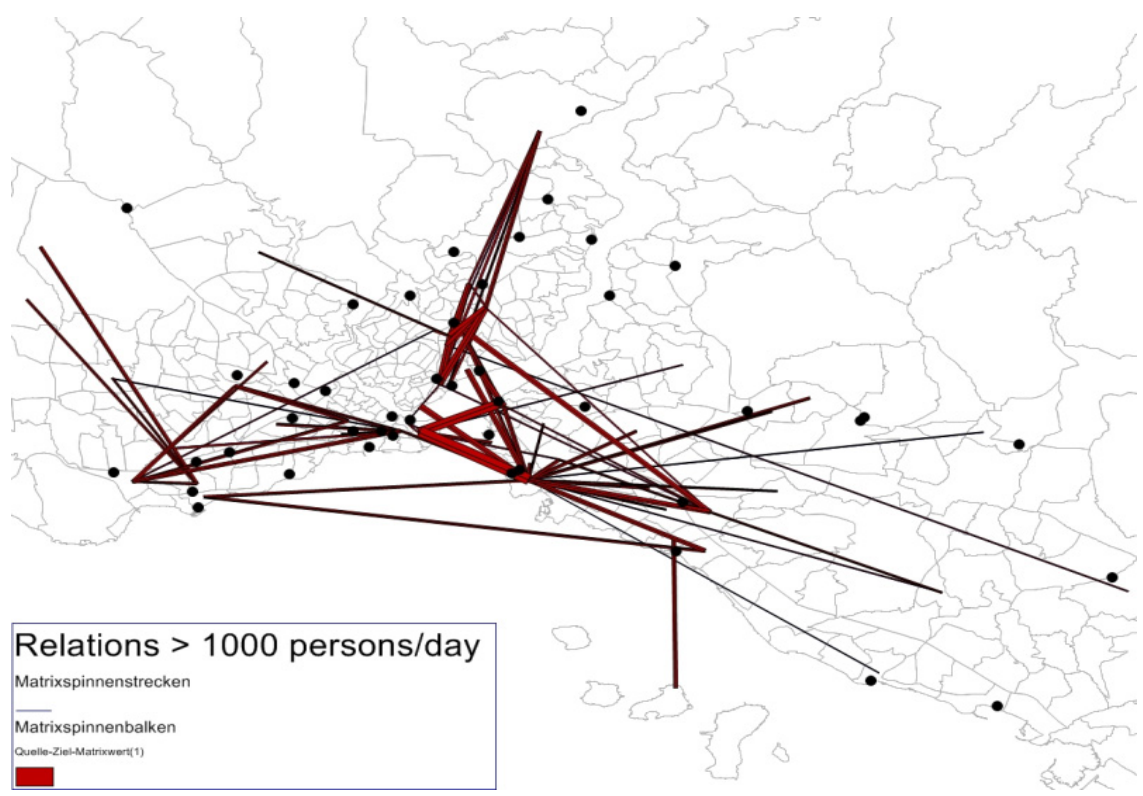

Figure 3: $\quad$ OD-matrix - trips between cells ( $>1.000$ persons/day).

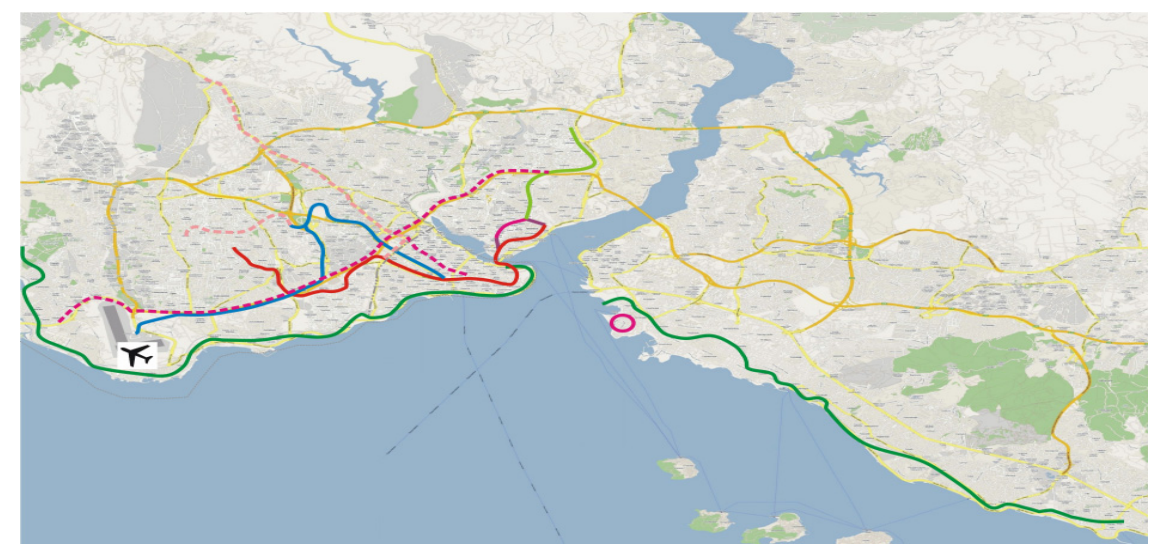

Figure 4: $\quad$ Most important arteries of the public transport network.

\section{Analysis of the current IETT bus network}

Figure 4 shows the major arteries of the public transport network in Istanbul. On the one hand the already existing lines of tram/LRT and railway, with the newly introduced Metrobus. On the other hand the backbones of the new bus network main roads and highways with own bus lanes for the fast bus-lines with main connection function. 


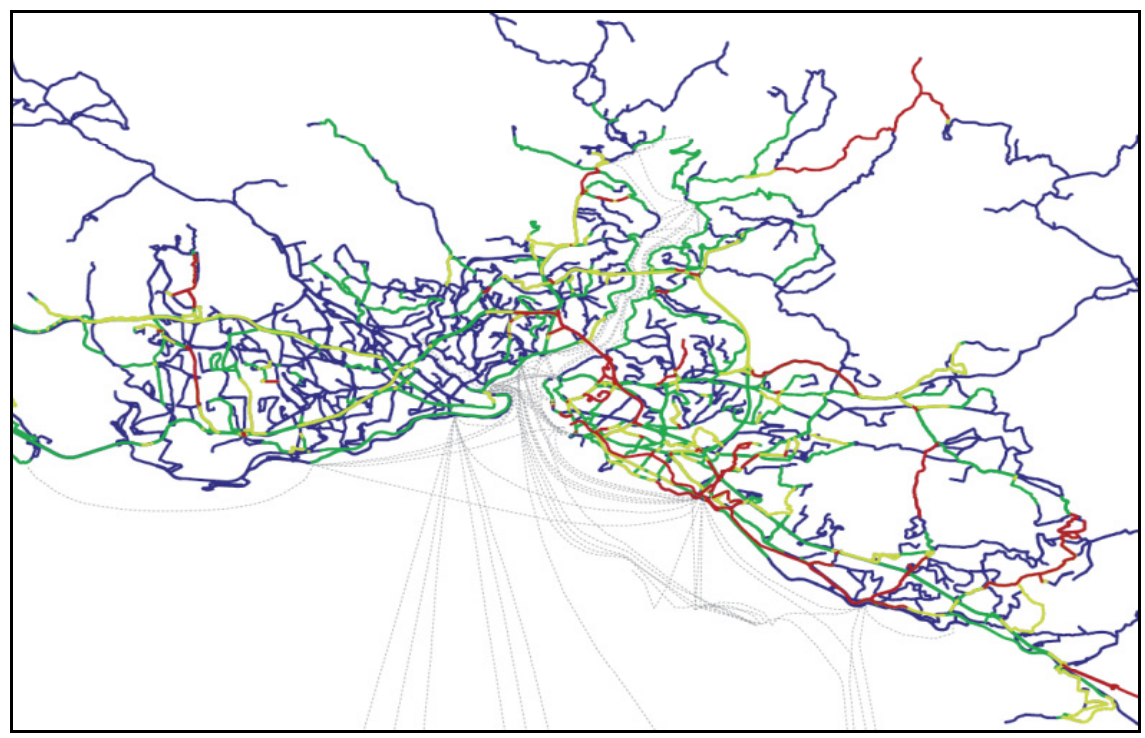

Figure 5: $\quad$ Capacity usage of the whole bus network.

The current capacity usage of the bus lines cannot be given exactly for each bus line out of the digital public transport model, but the capacity usage of the network sections can be given as a value over the whole day. The following Figure 5 shows the daily capacity usage on the different roads.

The parallel traffic to the soon realized major projects will be a problem for the IETT. Even though they are provided by other companies, the IETT has to adopt its transportation especially in these sections. Otherwise, the buses would run with a very bad capacity usage after the invention of the high quality systems Metrobus and new tramway. In our planning proposal, the reduction of parallel capacities plays a major role. To get an impression of the daily bus traffic in Istanbul, it is useful to visualize the daily IETT bus trips (from the schedules) and the requested passenger trips (out of the OD-Matrix).

Some guidelines are given from IETT for optimisation process. These are, Planned light railway tram, Metrobus lines; The major projects concerning the new light railway tram and Metrobus lines are considered as realized. These new lines will start in 2007 or 2008 and are therefore part of the assumed status quo network. No parallel traffic of bus lines to new railway or Metrobus lines; There should not be any parallel bus lines to lines of light rail transit or the Metrobus as they have similar routes and distances between the stops. The bus lines that run within little distance of the railway lines (Banliyö-Trains) and the metro (4. Levent - Taksim) are not affected, as these transport systems have greater distances between the stops so that the buses can be used for providing additional capacities and a better. No bus lines longer than $20 \mathrm{~km}$; In order to increase the degree of punctuality IETT wants all lines not to be longer than $20 \mathrm{~km}$ maximum. Therefore all lines longer than $20 \mathrm{~km}$ have to be split into several parts. The corresponding line routes have been split at important points like, 
Important bus transfer points, transfer points to railway, network situation (e.g. lot of lines coming together), and bus stop on a backbone road.

There are different instruments for the optimization of public transport networks. The choice of the right instruments must be made carefully and under consideration of the special circumstances of the traffic region.

- Reduction of Parallel Capacity. Several bus lines are running parallel to the new tramway line TR3 Topkapi - Edirnekapi - Sultanciftligi or the new metrobus line MB1 Mecideyeköy - Avcilar. Two cases of parallel traffic have to be distinguished: lines with a high percentage of identical way and, lines with a high percentage of parallel running without using exactly the same way.

- New Line Routes. Alternative line routes should run on fast roads if possible to gain savings in time and money. For this reason line routes running over the E-80 highway in Anadolu or in Istanbul are possible. By visualizing the load as well as the originating and terminating traffic in the corresponding traffic cells we could check if it is suitable to lead lines on these highways.

- Reduction of Trips in Case of Low Capacity Usage. Given data only include the daily traffic flow and the amount over time for the whole day. Due to the fact that do not having data about the traffic flow for individual hours, it is not possible to make a difference between the morning and the evening peak hour. For the reasons mentioned above, the proposals for the optimization of the capacity usage base on the daily traffic flow.

- Acceleration of Buses. Acceleration of buses is one of the most efficient ways of optimization. It is also the most planning intensive and challenging way of optimization. Acceleration of bus system is urgently needed to realize a road independent public transport backbone system for a global metropolitan city as Istanbul (Railways and Metro buses can not be realized everywhere).

Benefits of the acceleration of bus traffic are an increase of the reliability of travel time of public transport, an increase in the attractiveness of buses to the bus users, the facilitation of the bus circulation, improved accessibility, increased speed in bus services (bus lanes gain from 20 to $30 \%$ of travel times), and an increase in efficiency from the IETT's point of view (saving buses = saving money).

\section{Results of optimization}

After showing some details of possible savings and optimizations for the Istanbul public transport network, the global savings and figures for the whole network can be presented. It is necessary to split the passengers' point of view and the IETT's point of view, because sometimes the aims of both are not equal.

The length of a huge amount of bus lines will be changed due to the planning restrictions given by IETT. The cutting was done for all variations: IETT only, shared lines and private bus lines only. The global statistics for the complete network is shown in Table 1. 
Table 1: $\quad$ Length statistic of bus lines.

\begin{tabular}{|c|c|c|c|c|}
\hline \multirow{2}{*}{$\begin{array}{c}\text { Length of IETT } \\
\text { lines }\end{array}$} & \multicolumn{2}{|c|}{ before Optimization } & \multicolumn{2}{c|}{ after Optimization } \\
\cline { 2 - 5 } & amount & percentage & am ount & percentage \\
\hline$>=25 \mathrm{Km}$ & 66 & $15 \%$ & 23 & $5 \%$ \\
\hline$>=20 \mathrm{Km}$ & 49 & $11 \%$ & 36 & $9 \%$ \\
\hline$>=15 \mathrm{Km}$ & 100 & $23 \%$ & 90 & $21 \%$ \\
\hline$>=10 \mathrm{Km}$ & 126 & $29 \%$ & 147 & $35 \%$ \\
\hline$>=7,5 \mathrm{Km}$ & 55 & $13 \%$ & 56 & $13 \%$ \\
\hline$>=5 \mathrm{Km}$ & 28 & $6 \%$ & 39 & $9 \%$ \\
\hline$<5 \mathrm{Km}$ & 13 & $3 \%$ & 28 & $7 \%$ \\
\hline \hline
\end{tabular}

From the experience of other metropolitan regions and lot of projects, it is possible to predict, that the number of passengers can increase in a significant dimension when travel times are reduced. This is a very central result of the project, that IETT can raise quality of public transportation and thereby also the amount of passengers after the invention of the presented optimizations (especially the acceleration).

The exact figure of the increase of passengers and the change in the modal split behaviour is not easy to prophesy. With the detailed data out of our digital public transport model, we've been able to extract the travel time matrix between all traffic cells before and after the optimization (about 36.000 relations).

Most of the origin-destination relations were accelerated by the different planning proposals. The relations with an equal or worse travel time do not profit from the modelled acceleration measures or are affected from the increased need of transfers.

To be as exact as possible, we introduced a so-called "elasticity" factor. First, It is generated the ratio of all relations before and after optimization and then multiplied the amount of passengers on all faster relations with a conservative factor of $20 \%$. To give an example, that means if on a special relation over the whole day with 1.000 passengers where the travel time can be reduced about $10 \%$, we did calculate in the final origin-destination matrix with the new amount of 1.020 passengers in future (after a complete realization of the proposed optimization).

The following statistic shows in Table 2 the effects for the passengers, when all the described measured are realized in the bus network of Istanbul.

Considering the economic value of one passenger hour $(3,75 \mathrm{YTL}=3.75 \mathrm{New}$ Turkish Liras), the economic saving is: saving per day: 210.000, hours of journey time, saving per year: 76.650 .000 hours of journey time, Economic value per year: 287.437.500 YTL (1YTL=0.8 USD).

For the IETT, there will be a huge saving of bus kilometres and bus hours, resulting from the proposed changes. The following reductions as shown in Table 3 can be exported out of the digital public transport model. 
Table 2: $\quad$ Statistics of passenger data.

\begin{tabular}{|c|c|c|c|}
\hline Parameter of passenger statistics & $\begin{array}{c}\text { before } \\
\text { Optimization }\end{array}$ & $\begin{array}{c}\text { after } \\
\text { Optimization }\end{array}$ & variation $[\%]$ \\
\hline Average Journeytime [min] & 79 & 68 & $-14 \%$ \\
\hline Average Traveltime [min] & 54 & 44 & $-19 \%$ \\
\hline Average Travellength [km] & 24,0 & 24,0 & $0 \%$ \\
\hline Ratio of journeys without transfers & $51 \%$ & $49 \%$ & $-4 \%$ \\
\hline Ratio of journeys with one transfer & $35 \%$ & $35 \%$ & $0 \%$ \\
\hline Ratio of journeys with two or more transfers & $14 \%$ & $16 \%$ & $15 \%$ \\
\hline Average speed (whole journey) [km/h] & 18,2 & 21,0 & $15 \%$ \\
\hline Average speed (in vehicle) $[\mathrm{km} / \mathrm{h}]$ & 34,3 & 44,0 & $28 \%$ \\
\hline Total Journeytime [h] & 2.318 .000 & 2.045 .000 & $-12 \%$ \\
\hline Total Traveltime [h] & 1.599 .000 & 1.316 .000 & $-18 \%$ \\
\hline $\begin{array}{l}\text { Passenger hours per day } \\
\text { [IETT, railway, seaway] }\end{array}$ & 1.232 .000 & 979.000 & $-21 \%$ \\
\hline Total Travellength [km] & 22.700 .000 & 23.202 .000 & $2 \%$ \\
\hline $\begin{array}{l}\text { Directness (amount of necessary } \\
\text { changes per trip over all) }\end{array}$ & 0,651 & 0,703 & $8 \%$ \\
\hline
\end{tabular}

Table 3: $\quad$ Effects of optimization for IETT buses.

\begin{tabular}{|l|r|r|c|}
\hline Parameter of bus statistics & $\begin{array}{r}\text { before } \\
\text { Optimization }\end{array}$ & $\begin{array}{c}\text { after } \\
\text { Optimization }\end{array}$ & $\begin{array}{c}\text { variation } \\
\text { [\%] }\end{array}$ \\
\hline $\begin{array}{l}\text { Passengers per day in the OD-matrix } \\
\text { [IETT, railway, seaway] }\end{array}$ & 1.879 .000 & 1.909 .000 & $2 \%$ \\
\hline Passengers in the morning peak hour & 216.085 & 219.535 & $2 \%$ \\
\hline Number of bus stops & 3.641 & 3.617 & $-1 \%$ \\
\hline Lines served by IETT busses & 437 & 419 & $-4 \%$ \\
\hline Number of IETT busses in daily service & 2.513 & 2.170 & $-14 \%$ \\
\hline Total length of lines [km] (both directions) & 14.400 & 12.500 & $-13 \%$ \\
\hline Bus-kilometers per day & 488.000 & 436.000 & $-11 \%$ \\
\hline Bus-hours per day & 34.000 & 21.700 & $-36 \%$ \\
\hline Average Speed of busses (Km/h over all) & 14,4 & 20,1 & $40 \%$ \\
\hline Expenses per day, for all bus kilometers [YTL] & 1.664 .080 & 1.486 .760 & $-11 \%$ \\
\hline Savings per day, for all bus kilometers [YTL] & & 177.320 & \\
\hline
\end{tabular}

Savings by reduction of bus kilometer per year:

64.721 .800 YTL

\section{Conclusion}

With this project "Optimization of Bus Transport in Istanbul", the IETT has a powerful tool with a lot of information and detailed planning proposals to realize changes. The results and possible savings for passengers and carriers have been calculated and did show the huge potential from the economic point of view.

What IETT can do further on to improve its public transport, it is summarized in the above chapter. As mentioned, the evaluation of all further planning of IETT and others, affecting transportation and mobility in Istanbul, can be consulted with the information and details out of the digital public transport model. 


\section{References}

[1] www.ibb.gov.tr/ibb/doclib/pdf/bilgihizmetleri/yayinlar/bultenler/2003/169. pdf

[2] http://www.tfl.gov.uk/ttl/gettingaround/maps/buses/pdf/charingcrossquad2048.pdf

[3] Optimization of Bus Transport in Istanbul, Report for IETT, Sertem-ZIV Consortium, May 2007, Istanbul. 